\title{
BMJ Open Priority setting of vaccine introduction in Bangladesh: a multicriteria decision analysis study
}

\author{
Mohammad Sabbir Haider (D) ,,2 Sitaporn Youngkong (D) ,1,3 \\ Montarat Thavorncharoensap (D) , 1,3 Praveen Thokala (i) ${ }^{4}$
}

To cite: Haider MS, Youngkong S, Thavorncharoensap M, et al. Priority setting of vaccine introduction in Bangladesh: a multicriteria decision analysis study. BMJ Open 2022;12:e054219. doi:10.1136/ bmjopen-2021-054219

- Prepublication history and additional supplemental material for this paper are available online. To view these files, please visit the journal online (http://dx.doi.org/10.1136/ bmjopen-2021-054219).

Received 08 June 2021 Accepted 27 January 2022

Check for updates

(C) Author(s) (or their employer(s)) 2022. Re-use permitted under CC BY. Published by BMJ.

${ }^{1}$ Mahidol University Health Technology Assessment (MUHTA) Graduate Program, Mahidol University, Bangkok, Thailand

${ }^{2}$ Directorate General of Health Services, Government of Bangladesh Ministry of Health and Family Welfare, Dhaka, Bangladesh

${ }^{3}$ Social and Administrative Pharmacy Division, Department of Pharmacy, Faculty of Pharmacy, Mahidol University, Bangkok, Thailand

${ }^{4}$ Health Economics and Decision Science, School of Health and

Related Research (ScHARR), The University of Sheffield, Sheffield, UK

Correspondence to Dr Sitaporn Youngkong; sitaporn.you@mahidol.edu

\section{ABSTRACT}

Objective To prioritise vaccines for introduction in Bangladesh.

Methods Multicriteria decision analysis (MCDA) process was used to prioritise potential vaccines for introduction in Bangladesh. A set of criteria were identified, weighted and assigned scores by relevant stakeholders $(n=14)$ during workshop $A$. The performance matrix of the data of vaccines against the criteria set was constructed and validated with the experts $(n=6)$ in workshop $B$. The vaccines were ranked and appraised by another group of stakeholders $(n=10)$ in workshop $C$, and the final workshop $D$ involved the dissemination of the findings to decision-makers $(n=28)$.

Results Five criteria including incidence rate, case fatality rate, vaccine efficacy, size of the population at risk and type of population at risk were used quantitatively to evaluate and to score the vaccines. Two other criteria, cost-effectiveness and outbreak potentiality, were considered qualitatively. On deliberation, the Japanese encephalitis (JE) vaccine was ranked top to be recommended for introduction in Bangladesh.

Conclusions Based on the MCDA results, JE vaccine is planned to be recommended to the decision-makers for introduction into the national vaccine benefit package. The policymakers support the use of systematic evidencebased decision-making processes such as MCDA for vaccine introduction in Bangladesh, and to prioritise health interventions in the country.

\section{INTRODUCTION}

Vaccination is the most effective public health measure to prevent infectious diseases. ${ }^{1} 2$ Governments in developing countries prefer to invest in vaccination programmes that can be financially sustainable ${ }^{3-5}$ and while countries often consider cost-effectiveness, this should not be the only criterion for the selection of interventions. ${ }^{67}$ Different criteria, such as disease severity, effectiveness, accessibility, quality of care and equity, should be considered during healthcare priority setting. ${ }^{8}$

Decision-making around the introduction of new vaccines in the healthcare benefit package is complex. ${ }^{9}$ There are systematic and evidence-based methods, ${ }^{10}$ using priority

\section{Strengths and limitations of this study}

- Multicriteria decision analysis (MCDA) process was used to support vaccine introduction decisionmaking in Bangladesh, contributing to transparency and evidence-informed priority setting.

- Participation of a wide range of stakeholders in this MCDA study ensured the transparency and accountability of decision-making, which is essential for a fair priority setting process.

- Data on the vaccines on the different criteria were gathered from systematic evidence synthesis and validated with experts, and good practice MCDA guidance was followed to elicit the preferences and rank the list of vaccines.

- Different sets of stakeholders took part in the workshops, resulting in a lack of a consistent group of stakeholders (and hence values or preferences) throughout the MCDA process.

- Stakeholders from private sectors and representatives of patient groups were not involved in the process, leading to uncertainty in accountability of the results to those stakeholders.

setting to allocate the scarce resources to meet increasing demand. ${ }^{11}$ Multicriteria decision analysis (MCDA) is one such approach which evaluates different options considering multiple criteria in an explicit manner, ${ }^{12}$ to aid decision-makers to make rational decisions. ${ }^{13}$ MCDA can be a useful approach to support inclusion of health interventions in the benefit package. ${ }^{7}$

Vaccine preventable diseases such as dengue, human papillomavirus (HPV), influenza, Japanese encephalitis (JE) and typhoid are prevalent in Bangladesh. ${ }^{14-18}$ These diseases can be prevented by the introduction of new or underused vaccines by the government of Bangladesh. However, new vaccines have considerable budget impact and need to be prioritised for introduction into the benefit package. ${ }^{19}$ In the past, decisionmaking for vaccine introduction was ad-hoc 
but there is increasing interest in prioritisation using systematic evaluation of multiple criteria. ${ }^{19}$

As such, we conducted an MCDA study to support prioritisation of vaccines for introduction in the benefit package in Bangladesh. The aims of the study are to support prioritisation of health interventions using an evidence-based systematic process incorporating multiple criteria and involving key relevant stakeholders, and to provide national decision-makers with scientific recommendations on vaccine introduction to better use the limited resources in Bangladesh.

\section{METHODS}

We followed the steps outlined in good practice guidelines for the use of MCDA in healthcare..$^{20}$ As stakeholder involvement is key, we conducted four workshops (between October 2019 and January 2020) with the relevant stakeholders during the MCDA process. The steps and the workshops are described in further detail below.

\section{Identifying the list of potential vaccines for introduction}

The potential vaccines for prioritisation were identified from the recommendations of the WHO, Gavi the vaccine alliance, and Centers for Disease Control and Prevention in the USA (CDC-US). Vaccines which were currently in the expanded programme on immunisation (EPI) programme of the neighbouring countries were also considered. From these sources, vaccines that were not yet introduced in Bangladesh were identified as potential vaccines to be evaluated.

\section{Selecting criteria for vaccine introduction in Bangladesh}

A three-step process was used to select criteria for vaccine introduction in Bangladesh. First, a systematic review was conducted to identify all potential criteria for vaccine introduction in Bangladesh, which is described elsewhere in detail. ${ }^{22}$ Second, from this long list of criteria, a core team of three public health experts of Bangladesh (including the lead author, MSH) excluded criteria that cannot be quantified (eg, political will) and those that were mentioned less frequently.

Finally, the potential criteria list was ranked in workshop A (WS-A) in October 2019, to identify the key criteria to be used for vaccine prioritisation. Stakeholders $(\mathrm{n}=14)$ included paediatricians $(\mathrm{n}=1)$, public health experts $(n=6)$, virologists $(n=2)$, epidemiologists $(n=4)$ and health economists $(n=1)$. In terms of affiliation, these stakeholders $(n=14)$ were from directorate office $(n=4)$, technical institutes $(n=4)$, non-government organisations (NGOs) ( $\mathrm{n}=3$ ), National Immunization Technical Advisory Group (NITAG) $(\mathrm{n}=2)$ and health professional associations $(n=1)$. The criteria, along with their definitions, were presented to the stakeholders (online supplementary A) who were then asked to rank each criterion from ' 1 to 10 ', where ' 1 ' was the most preferable and ' 10 ' was the least preferable criterion. The ranked order of criteria was transformed into ranking weight using the rank order centroid (ROG) method ${ }^{23}$ Criteria were ranked based on the mean ROC weight, and the stakeholders selected a set of criteria by consensus to be used in the prioritisation of vaccines.

\section{Weighting and scoring}

In the same workshop (WS-A), the stakeholders weighted the criteria using direct rating methods. Stakeholders discussed and then agreed by consensus to assign points to each criterion on a scale of $0-100$, where ' 0 ' depicted the least important, and ' 100 ' represented the most important. To calculate the weights, the points assigned for each criterion was normalised (ie, by dividing the points allocated to each criterion by the sum of points of all criteria) using Equation 1. ${ }^{24} 25$

$$
w_{i}=p_{i} / \sum p_{i}
$$

where, $w_{i}$ is the normalised weight of criterion $i ; i$ is the index of criterion; $p_{i}$ is the points allocated to each criterion.

For scoring, the levels of criteria were identified by the core team from literature review and expert opinion. These were presented to the stakeholders in WS-A, who then assigned scores to the levels in each criterion individually. The stakeholders then deliberated on these individual scores and assigned scores to each level of the criterion by consensus. The range of scores was between 0 and 1 , where, ' 0 ' depicted the lowest score, and ' 1 ' represented the highest score.

\section{Gathering evidence}

Data for the potential vaccines were collected from databases and reports from key organisations such as EPI, Communicable Disease Control of Directorate General of Health Services (CDC-DGHS), Institute of Epidemiology, Disease Control and Research and International Centre for Diarrhoeal Disease and Research, Bangladesh. A performance matrix was constructed, which presents data for each vaccine against the set of criteria. Then, workshop B (WS-B) was arranged in November 2019 to validate the data with a group of public health and vaccine experts in the country $(n=6)$, that is, public health experts who were working in the disease surveillance $(n=2)$, DGHS $(n=2)$, Health Economics Unit $(n=1)$ and NITAG $(n=1)$. After reviewing and validation, they signed off on the performance matrix.

\section{Rank ordering the potential vaccines}

The scores for the different levels from the WS-A were combined with the validated performance matrix from the WS-B to calculate the scores for each vaccine on the different criteria. Then, using the additive method ${ }^{21}$ (see Equation 2), ${ }^{26}$ the scores of each vaccine corresponding to the criteria level were multiplied by the weight of each criterion (from WS-A) to calculate the total scores of each potential vaccine. The vaccines were ranked based on the total scores of each vaccine, with the highest total score ranked top, and the next highest total second, and so on. 


$$
V_{j}=\sum C_{i j} * W_{i}
$$

where $V_{j}$ is the total value for alternative $j ; C_{i j}$ is the score of alternative $j$ on criteria $i$; $W_{i}$ is the weight attached to criteria $i$.

\section{Appraising the rank of vaccines}

Workshop C (WS-C) was conducted in December 2019 to appraise the vaccines. Stakeholders included the experts in the area of vaccination $(\mathrm{n}=10)$, that is, epidemiologists $(n=2)$, virologists $(n=3)$, infectious disease specialists $(n=2)$, surveillance experts $(n=1)$ and members of the vaccination policy programme $(n=2)$. The performance matrix of the potential vaccines was provided in a paper-based format (online supplementary B) and the stakeholders were asked to assign the rank to the seven potential vaccines individually, where ' 1 ' was the most preferable vaccine and ' 7 ' was the least preferable vaccine. The mean rank of each vaccine was calculated from the ranks provided by each stakeholder, using the ROC method. ${ }^{23}$

The ranking analysis of vaccines retrieved from step 5 (based on findings from WS-A and WS-B) were then presented to the stakeholders, along with the evidence of the cost-effectiveness and outbreak potentiality of each vaccine. Stakeholders then considered all this information and deliberated to reach a consensus on a final ranking of vaccines.

\section{Application of vaccine prioritisation process in Bangladesh health system}

A final workshop D was organised in January 2020 with the policymakers $(n=28)$ working in vaccine decision-making, vaccination programme implementation, vaccine-related research and disease surveillance. The stakeholders were representatives from the ministry of health $(n=12)$, the directorate office of health $(n=9)$, development partners $(n=2)$, health professional associations $(n=2)$ and NGOs $(n=3)$. This workshop involved the dissemination of the whole vaccine prioritisation process (including the selection of criteria, identification of vaccines and the MCDA methods), along with the findings.

\section{Patient and public involvement}

Patients and the general public were not involved in this study.

\section{RESULTS}

\section{The list of potential vaccines for introduction in Bangladesh}

WHO recommended 23 vaccines for routine vaccination globally, while the CDC-US recommended 16 vaccines and Gavi the vaccine alliance provided support against 16 infectious diseases. ${ }^{27-29}$ Bangladesh so far introduced 10 vaccines in their benefit package and two additional vaccines for the Haj pilgrimage travellers. Therefore, there were 11 vaccines not included yet in the Bangladesh health benefit package. After discussion among the core team and vaccine experts, four vaccines were excluded:
Table 1 Selecting criteria based on ranking from the WS-A

\begin{tabular}{lcc}
\hline & Rank & \\
\cline { 2 - 3 } Criteria & $\begin{array}{l}\text { Using the } \\
\text { mean of } \\
\text { individuals }\end{array}$ & $\begin{array}{l}\text { Consensus } \\
\text { after } \\
\text { deliberation }\end{array}$ \\
\hline Incidence rate of disease* $^{*}$ & 1 & 1 \\
Case fatality rate* $^{*}$ & 2 & 2 \\
Vaccine efficacy* $^{*}$ & 3 & 3 \\
\hline Size of population at risk* & 5 & 4 \\
\hline Type of population at risk* & 6 & 5 \\
\hline Outbreak potentiality & 4 & 6 \\
\hline Cost-effectiveness & 7 & 7 \\
\hline Severity of disease & 8 & 8 \\
\hline Global target & 9 & 9 \\
\hline Equity & 10 & 10 \\
\hline
\end{tabular}

${ }^{*}$ Criteria selected for vaccine prioritisation in Bangladesh. WS-A, workshop A.

tick-borne encephalitis and yellow fever as Bangladesh lacked incidence data for these diseases, and varicella and hepatitis A virus vaccines as they were not included in the benefit package of the neighbouring countries. Seven vaccines (ie, cholera, dengue, typhoid, HPV, influenza, JE and rotavirus) were then selected for consideration in the priority setting process.

\section{Prioritisation criteria for vaccine introduction in Bangladesh}

Sixty-seven criteria were identified in the systematic review, from which the core team identified 10 criteria as being potentially most relevant (table 1 ). Definitions of these 10 criteria were derived from the literature review. ${ }^{30-32}$

In the WS-A, stakeholders discussed the importance of each of these 10 criteria and justification for inclusion in the set of prioritisation criteria to be used for vaccine introduction in Bangladesh. Participants ranked individually first and after deliberation, consensus was achieved. Table 1 presents the mean of individual ranking using ROC method and the final consensus ranking. Based on these rankings, stakeholders selected the top five criteria for vaccine prioritisation in Bangladesh (ie, incidence rate, case fatality rate, vaccine efficacy, size of population at risk and type of population at risk). In addition to these five quantitative criteria, stakeholders also decided to include two qualitative criteria: 'outbreak potentiality' and 'cost-effectiveness'. These two criteria were not weighted or scored explicitly, but were used in deliberative discussions.

\section{Performance matrix}

The data on the performance of each of seven vaccines against the prioritisation criteria are presented in table 2. The table presents data on the five quantitative criteria used for weighting and scoring, as well as the two qualitative criteria that were used in deliberative discussions. 


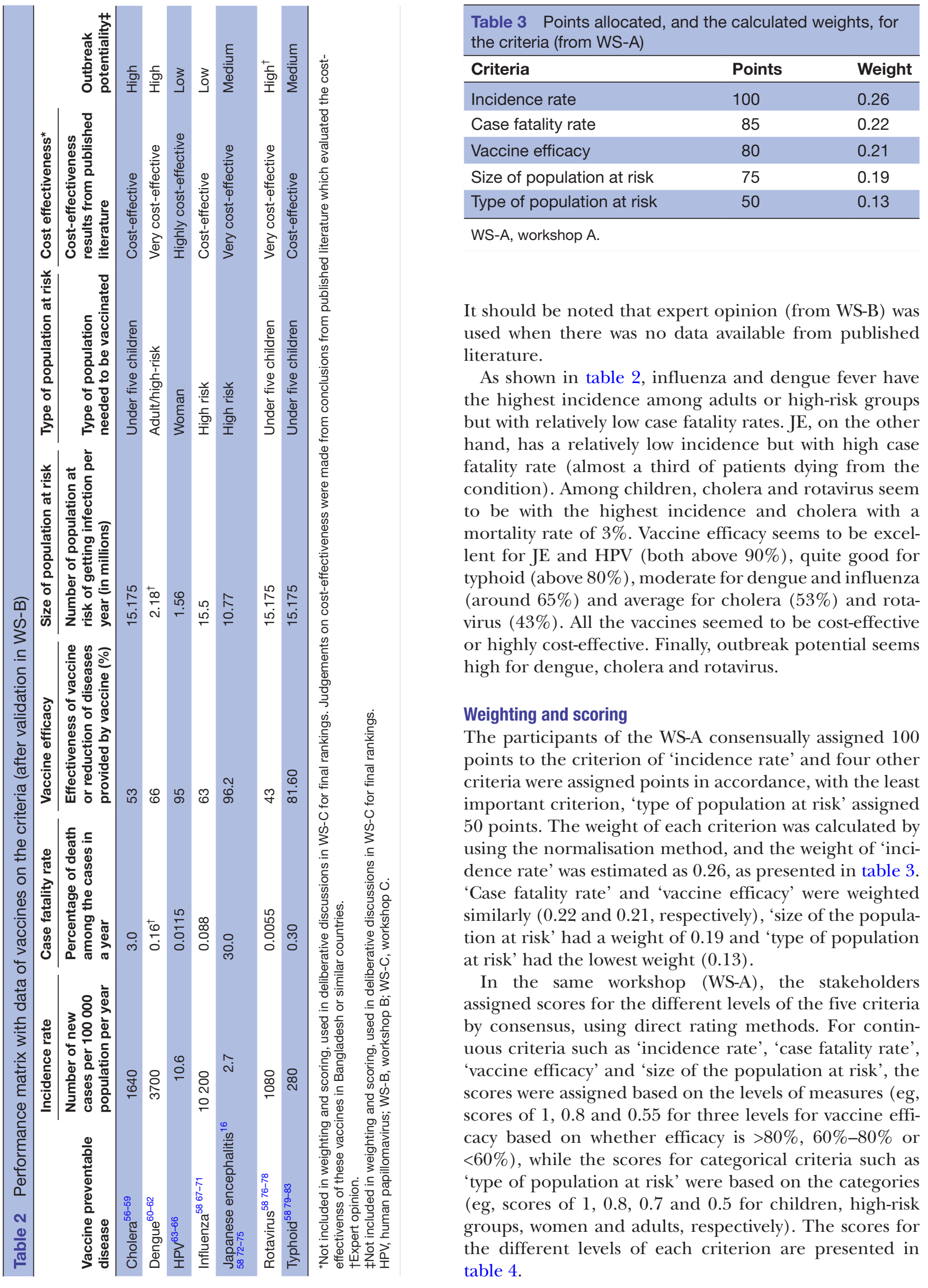




\begin{tabular}{|c|c|c|}
\hline Criteria & Levels & Score \\
\hline \multirow[t]{4}{*}{ Incidence rate } & Level 1: >1000/100 000 & 1.0 \\
\hline & Level 2: 100-1000/100 000 & 0.8 \\
\hline & Level 3: 10-100/100 000 & 0.5 \\
\hline & Level 4: <10/100 000 & 0.3 \\
\hline \multirow[t]{3}{*}{ Case fatality rate } & Level $1>10 \%$ & 1.0 \\
\hline & Level 2: 1\%-10\% & 0.8 \\
\hline & Level 3: $<1 \%$ & 0.4 \\
\hline \multirow[t]{3}{*}{ Vaccine efficacy } & Level 1: >80\% & 1.0 \\
\hline & Level 2: 60\%-79\% & 0.8 \\
\hline & Level 3: <60\% & 0.55 \\
\hline \multirow{4}{*}{$\begin{array}{l}\text { Size of population at } \\
\text { risk }\end{array}$} & Level 1: >10 million & 1.0 \\
\hline & Level 2: 1-10 million & 0.8 \\
\hline & Level 3: 100 000-1 million & 0.5 \\
\hline & Level 4: <100 000 & 0.3 \\
\hline \multirow{4}{*}{$\begin{array}{l}\text { Type of population } \\
\text { at risk }\end{array}$} & Level A: children ( $<5$ years) & 1.0 \\
\hline & Level C: high-risk group & 0.8 \\
\hline & Level B: women & 0.7 \\
\hline & Level D: adult & 0.5 \\
\hline
\end{tabular}

WS-A, workshop A.

\section{Rank ordering the potential vaccines}

After combining the findings from tables 2-4 to estimate the score and weights (ie, the weights from WS-A, and the scores by combining the different levels from WS-A with the data from performance matrix validated in WS-B), the core team performed analysis of seven vaccines and produced the ranking results, as shown in table 5. Cholera vaccine was top-ranked with the highest total score of 0.86 primarily because it affects children, has a high incidence rate, high case fatality rate and with high size of population at risk. Despite having effective vaccines, JE and HPV ranked bottom (with scores of 0.74 and 0.68 , respectively) because they have a low incidence rate and low size of population at risk.

\section{Appraising the rank of vaccines}

In the WS-C, the stakeholders reviewed the performance matrix and each stakeholder ranked the vaccines individually first. The mean of their individual rankings are presented in table 6 . Based on the deliberations of performance matrix, the stakeholders in WS-C ranked HPV, JE and rotavirus, as the first, second and third, respectively. The stakeholders discussed and highlighted the importance of the vaccine for women, which was why HPV was ranked as the first. Then, they gave priority to vaccines with high incidence rate and high case fatality rate; therefore, JE and rotavirus vaccines were ranked next highest. This contrasts with the findings from the quantitative MCDA exercise by the core team (see table 5 using findings from WS-A and WS-B), which suggested cholera, typhoid and influenza as the top three ranking vaccines.

The results of ranking by the core team (table 5) were then presented to the stakeholders in WS-C, along with the information on the potentiality of outbreak of the diseases and cost-effectiveness (see table 2). After considering all this information, the stakeholders adjusted the ranking by consensus and the final ranking is presented in table 6 . HPV, JE and rotavirus still remained top three but the ranking order changed with JE, HPV and rotavirus being first, second and third, respectively.

\section{Application of vaccine prioritisation process in Bangladesh health system}

After dissemination of the findings, the policymakers agreed on the importance of appraising new interventions scientifically and supported the use of MCDA in the priority setting process for vaccine introduction decisionmaking. The key personnel of the ministry of health and family welfare, Bangladesh, stated that 'It is better for Bangladesh at present to have this system to prioritise vaccines in the country. Bangladesh, a lower-middle income country is graduating Gavi funding. So, we have to change our decisionmaking process from donor influenced decision-making to selfdecision-making'. Based on the MCDA results, JE vaccine is planned to be recommended to the decision-makers for introduction into the national vaccine benefit package. They also highlighted that after the selection of vaccines, the country should prepare for vaccine logistics such as cold-chain capacity and other programmatic issues.

\section{DISCUSSION}

\section{Summary of the study}

This study represents the first time an explicit priority setting process based on MCDA was used for the priortisation of vaccines in Bangladesh. Vaccines selected for prioritisation were those which were recommended by the international organisations but not included in health benefit package of Bangladesh. The potential multiple criteria were identified systematically from published literature, and shortlisted in two phases to select five quantitative criteria and two qualitative criteria for the evaluation of the vaccines. Weighting and scoring of the quantitative criteria were explicit and participatory, and the tools used for eliciting scores and weights were user friendly and well understood by the stakeholders. The final ranking of the vaccines was determined after deliberative discussions based on the performance matrix, which considered both quantitative criteria and qualitative criteria.

\section{Statement of the principal findings}

Through this explicit MCDA approach, JE vaccine was placed as the top-ranked vaccine and is planned to be recommended to the decision-makers for introduction into the national vaccine benefit package. The policymakers support the use of systematic evidence-based decision-making processes such as MCDA for vaccine 


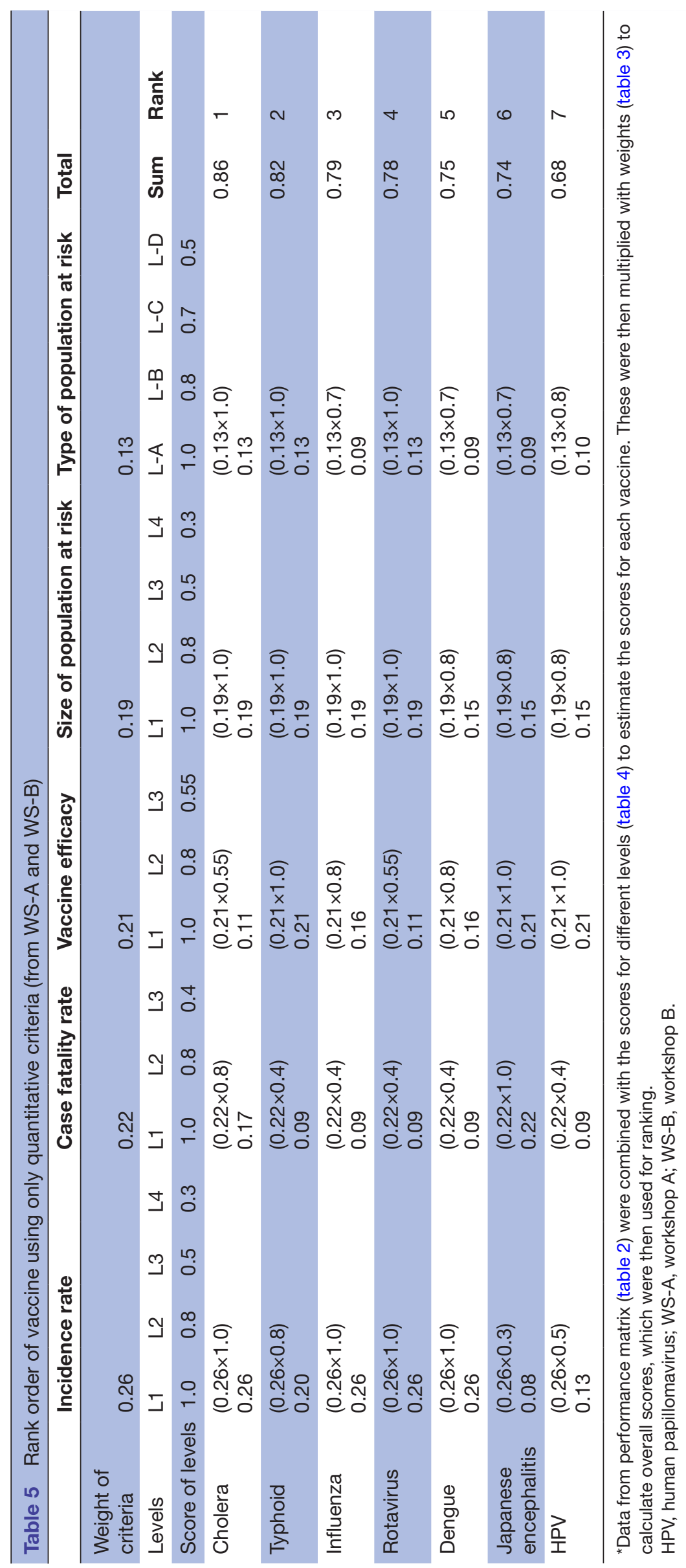


Table 6 Ranking of vaccines

\begin{tabular}{llll}
\hline Vaccine & $\begin{array}{l}\text { Ranking } \\
\text { from } \\
\text { WS-C }\end{array}$ & $\begin{array}{l}\text { Ranking from the } \\
\text { analysis of WS-A } \\
\text { and WS-B }\end{array}$ & $\begin{array}{l}\text { Final ranking } \\
\text { after deliberation } \\
\text { in WS-C* }\end{array}$ \\
\hline $\begin{array}{l}\text { Japanese } \\
\text { encephalitis }\end{array}$ & 2 & 6 & 1 \\
\hline HPV & 1 & 7 & 2 \\
\hline Rotavirus & 3 & 4 & 3 \\
\hline Cholera & 5 & 1 & 4 \\
\hline Typhoid & 4 & 2 & 5 \\
\hline Dengue & 7 & 5 & 6 \\
\hline Influenza & 6 & 3 & 7 \\
\hline
\end{tabular}

*including consideration of information on cost-effectiveness and outbreak potential.

HPV, human papillomavirus; WS-A, workshop A; WS-B, workshop B; WS-C, workshop C.

introduction in Bangladesh, and to prioritise health interventions in the country.

\section{Strengths of the study, and comparison to findings from other} studies

Stakeholder involvement

The MCDA process was supported by different stakeholders. Members of the different decision-making committees (NITAG), implementing bodies (EPI and others) and health professional associations were involved in every step of this study. Stakeholders of implementing agencies-EPI and CDC-DGHS-also participated in the deliberative process and ranking. NITAG members and members of National Committee for Immunization Practices also participated in the final decision-making workshop at the ministry level. Participation of stakeholders in this study ensured the transparency and accountability of decision-making, which is essential for a fair priority setting approach. ${ }^{33}$ The importance of involving different stakeholders during the decision-making of vaccine introduction is also highlighted in other countries such as South Korea, ${ }^{34}$ Oman, ${ }^{35}$ Indonesia ${ }^{36}$ and the Netherlands. ${ }^{37}$

\section{Criteria used in priority setting}

Incidence rate of the disease and case fatality rate criteria were weighted highly, indicating that disease burden was considered important for vaccine selection by the stakeholders. This finding is similar to other studies which suggest disease burden as the most common and important criterion considered by other low- and middleincome countries (LMICs) during national decisionmaking. ${ }^{19}{ }^{38-42}$ Efficacy of the vaccines was weighted as the next most important criterion suggesting that clinical effectiveness is also important.

\section{Deliberative MCDA}

The final ranking in this study was based on deliberation using the performance matrix, where the weights and scores were not explicit. Despite the lack of explicit weighting and scoring, deliberative discussions are considered to be a very important part of MCDA process as it allows a shared understanding of the data, criteria and priorities. Deliberation among stakeholders followed by simple ranking appears a feasible strategy for the prioritisation of vaccines for introduction in Bangladesh and other LMICs. Kenya and Iran selected vaccines by voting, whereas Oman, India and the Netherlands selected vaccines by expert evaluation which were evidencebased but not systematic. ${ }^{35} 374344$ Korea and Thailand selected vaccines systematically via evidence-based deliberation using DELPHI and MCDA techniques. ${ }^{3445}$ Recent consensus on the use of MCDA for Health Technology Assessment (HTA) ${ }^{46}$ recommends deliberative MCDA approach over quantitative MCDA. Furthermore, a recent study by WHO encouraged weighting and scoring as they help streamline the deliberative discussions. ${ }^{47}$ The methods used in our study, where the stakeholders deliberated the results from the quantitative MCDA and the performance matrix before finalising the ranking of vaccines, are in line with these recommendations.

\section{Implications for policymakers}

While decision-making around vaccines in LMICs has been driven by donor funding, our study shows that it is possible to perform prioritisation systematically using evidence-based MCDA approaches. Based on the results of the MCDA study, the top-ranked JE vaccine is planned to be recommended to the decision-makers for introduction into the national vaccine benefit package. Please note that the ranking of vaccines and the selection of $\mathrm{JE}$ vaccine is country specific and may not be applicable to other settings. It is noteworthy that decision-making itself is a dynamic process, and vaccine performance on some criteria is likely to change over time. Therefore, we recommend Bangladesh undertake this priority setting process routinely even though most of the countries evaluate vaccines to be introduced once. ${ }^{39} 404348-51$

\section{Limitations of the study}

Different sets of stakeholders took part in the three workshops, resulting in a lack of a consistent group of stakeholders (and hence values/preferences) throughout the MCDA process. The ranking from quantitative weighting and scoring (from WS-A and WS-B) was different to the ranking by the stakeholders in the WS-C, who ranked the vaccines after a deliberative process. This may be due to the differences in the stakeholder membership between the different workshops and the underlying differences in their preferences.

Furthermore, the vaccine ranking in WS-C was finalised after considering the cost-effectiveness and the outbreak potentiality criteria, as well as the quantitative ranking. Also, the stakeholder preferences were implicit in the WS-C while they were explicitly elicited in the ranking using quantitative weighting and scoring (from WS-A and WS-B). This highlights the importance of ensuring a consistent set of criteria and a consistent preference 
elicitation methodology throughout the MCDA process, along with a consistent group of stakeholders. If the membership, the criteria set or the methodology changes between the different workshops, there is a possibility that the ranking may change quite substantially.

Despite the inclusion of a wide variety of stakeholders, our study does not represent all stakeholders' perspectives. Stakeholders from private sectors and representatives of patient groups were not involved in the process leading to uncertainty in accountability of the results to those stakeholders.

Finally, in our study, the cost-effectiveness considerations and data of outbreak potentiality were included as qualitative criteria rather than quantitative criteria with explicit weighting and scoring. It is important to note that cost-effectiveness is not recommended as a criterion in the MCDA,,$^{52} 53$ as such, a pragmatic approach was taken to consider this information qualitatively rather than weighting and scoring. While decision-making around vaccines has typically been driven by donor funding assurance, financial considerations are highlighted as being key by stakeholders. Capacity building around economic evaluation and budget impact analysis of vaccines is needed in LMICs such as Bangladesh to support evidence-based priority setting combining MCDA with Value for Money approaches. ${ }^{53-55}$

\section{CONCLUSIONS}

This study presents the first application of MCDA to support vaccine prioritisation in Bangladesh health system. This study involved relevant stakeholders in priority setting process and achieved the objectives of prioritising the vaccines for introduction in Bangladesh in a transparent way, using systematic evidence-based decision-making. JE vaccine was placed as the topranked vaccine and is planned to be recommended to the decision-makers for introduction into the national vaccine benefit package. The use of MCDA to prioritise interventions in healthcare should be promoted as the decision-making process can be improved using systematic approaches.

Contributors MSH conceived and designed the study, collected data, analysed the results and drafted the manuscript. SY and PT helped in the study design, data analysis, interpretation of results and reviewed the manuscript. MT contributed to the design of the study and reviewed the manuscript. All authors discussed the findings of the study, edited and approved the manuscript. All authors are responsible for the overall content as guarantors.

Funding International Decision Support Initiative (iDSI) (OPP1087363)

Disclaimer The findings, interpretations and conclusions expressed in this article do not necessarily reflect the views of the funding agencies.

Competing interests The authors declared no potential conflicts of interest with respect to the research and authorship.

Patient consent for publication Not applicable.

Ethics approval Ethical clearance of this study was obtained from the Bangladesh Medical and Research Council (BMRC) and informed written consent was obtained from the stakeholders participating in the workshops.

Provenance and peer review Not commissioned; externally peer reviewed.
Data availability statement Data are available from the corresponding author. Email: sitaporn.you@mahidol.edu.

Supplemental material This content has been supplied by the author(s). It has not been vetted by BMJ Publishing Group Limited (BMJ) and may not have been peer-reviewed. Any opinions or recommendations discussed are solely those of the author(s) and are not endorsed by BMJ. BMJ disclaims all liability and responsibility arising from any reliance placed on the content. Where the content includes any translated material, BMJ does not warrant the accuracy and reliability of the translations (including but not limited to local regulations, clinical guidelines, terminology, drug names and drug dosages), and is not responsible for any error and/or omissions arising from translation and adaptation or otherwise.

Open access This is an open access article distributed in accordance with the Creative Commons Attribution 4.0 Unported (CC BY 4.0) license, which permits others to copy, redistribute, remix, transform and build upon this work for any purpose, provided the original work is properly cited, a link to the licence is given, and indication of whether changes were made. See: https://creativecommons.org/ licenses/by/4.0/.

\section{ORCID iDs}

Mohammad Sabbir Haider http://orcid.org/0000-0003-0013-0051

Sitaporn Youngkong http://orcid.org/0000-0002-2448-3954

Montarat Thavorncharoensap http://orcid.org/0000-0002-8256-2167

Praveen Thokala http://orcid.org/0000-0003-4122-2366

\section{REFERENCES}

1 Timmis JK, Black S, Rappuoli R. Improving accountability in vaccine decision-making. Expert Rev Vaccines 2017;16:1057-66.

2 Brenzel L, Wolfson LJ, Fox-Rushby J. Vaccine-Preventable Diseases-Chapter 20. Disease Control Priorities in Developing Countries:389-411.

3 Ehreth J. The value of vaccination: a global perspective. Vaccine 2003;21:4105-17.

4 Ehreth J. The global value of vaccination. Vaccine 2003;21:596-600.

5 Mauskopf J, Standaert B, Connolly MP, et al. Economic analysis of vaccination programs: an ISPOR good practices for outcomes research Task force report. Value Health 2018;21:1133-49.

6 Baltussen R, Jansen MP, Mikkelsen E, et al. Priority setting for universal health coverage: we need evidence-informed Deliberative processes, not just more evidence on cost-effectiveness. Int $J$ Health Policy Manag 2016;5:615-8.

7 Norheim OF. Ethical priority setting for universal health coverage: challenges in deciding upon fair distribution of health services. BMC Med 2016;14:75.

8 Youngkong S, Kapiriri L, Baltussen R. Setting priorities for health interventions in developing countries: a review of empirical studies. Trop Med Int Health 2009;14:930-9.

9 Munira SL, Fritzen SA. What influences government adoption of vaccines in developing countries? A policy process analysis. Soc Sci Med 2007;65:1751-64.

10 Baltussen R, Niessen L. Priority setting of health interventions: the need for multi-criteria decision analysis. Cost Eff Resour Alloc 2006;4:14.

11 Mitton C, Donaldson C. Health care priority setting: principles, practice and challenges. Cost Eff Resour Alloc 2004;2:3.

12 Thokala P, Duenas A. Multiple criteria decision analysis for health technology assessment. Value Health 2012;15:1172-81.

13 Marsh K, Goetghebeur M, Thokala P. Multi-Criteria decision analysis to support healthcare decisions. Springer, 2017.

14 Haque F, Hossain MJ, Kundu SK. Cholera Outbreaks in Urban Bangladesh. In: Sunnyvale, ed. 2011. Epidemiology. 3, 2013.

15 Hossain MJ, Gurley ES, Montgomery S, et al. Hospital-Based surveillance for Japanese encephalitis at four sites in Bangladesh, 2003-2005. Am J Trop Med Hyg 2010;82:344-9.

16 Paul RC, Rahman M, Gurley ES, et al. A novel low-cost approach to estimate the incidence of Japanese encephalitis in the catchment area of three hospitals in Bangladesh. Am J Trop Med Hyg 2011;85:379-85.

17 Hasan AZ, Saha S, Saha SK, et al. Using pneumococcal and rotavirus surveillance in vaccine decision-making: a series of case studies in Bangladesh, Armenia and the Gambia. Vaccine 2018;36:4939-43.

18 Dhar-Chowdhury P, Paul KK, Haque CE, Chowdhury PDP $\mathrm{KK}$, Hossain S, et al. Dengue seroprevalence, seroconversion and risk factors in Dhaka, Bangladesh. PLoS Negl Trop Dis 2017;11:e0005475. 
19 Uddin J, Sarma H, Bari TI, et al. Introduction of new vaccines: decision-making process in Bangladesh. $J$ Health Popul Nutr 2013;31:211-7

20 Marsh K, IJzerman M, Thokala P, et al. Multiple Criteria Decision Analysis for Health Care Decision Making--Emerging Good Practices: Report 2 of the ISPOR MCDA Emerging Good Practices Task Force. Value Health 2016;19:125-37.

21 Thokala P, Devlin N, Marsh K, et al. Multiple Criteria Decision Analysis for Health Care Decision Making--An Introduction: Report 1 of the ISPOR MCDA Emerging Good Practices Task Force. Value Health 2016;19:1-13.

22 Haider MS. Multi-Criteria Decision Analysis for Priority Setting of Vaccine Introduction in Bangladesh [Ph.D. Thesis] 2020:Mahidol University.

23 Roszkowska E. Rank ordering criteria weighting methods-a comparative overview; 2013.

24 Podviezko A, Podvezko V. Influence of data transformation on multicriteria evaluation result. Procedia Engineering 2015;122:151-7.

25 Normalization techniques for multi-criteria decision making: analytical hierarchy process case study.2016,Springer

26 Marsh K, Thokala P, Mühlbacher A. Incorporating Preferences and Priorities into MCDA: Selecting an Appropriate Scoring and Weighting Technique. In: Marsh K, Goetghebeur M, Thokala P, eds. Multi-Criteria decision analysis to support healthcare decisions. Cham: Springer International Publishing, 2017: 47-66.

27 World Health Organization. WHO recommendations for routine immunization - summary tables 2019 [updated 26 April 2019; cited 201921 November 2019], 2019. Available: https://www.who. int/immunization/policy/immunization_tables/en/ [Accessed 21 November, 2019].

28 Gavi The Vaccine Alliance. Gavi, The Vaccine Alliance-Vaccine Support 2019 [cited 201921 November 2019]. Available: https:// www.gavi.org/programmes-impact/types-support/vaccine-support

29 Centers for Disease Control and Prevention. Centers for disease control and prevention 2019, 2019. Available: https://www.cdc.gov/ vaccines/ [Accessed 21 November 2019].

30 Rashid K. Hyder's Textbook of community Medicine and public Health. Dhaka RHM publishers; 2008.

31 World Health Organization. World Health Statistics 2012 - Indicator compendium: World Health Organization; 2012.

32 World Health Organization. Global reference list of 100 core health indicators: World Health organization; 2015.

33 Daniels N. Accountability for Reasonableness. BMJ 2000;321:1300-1.

34 Choe YJ, Han OP, Cho $\mathrm{H}$, et al. Prioritization of the introduction of new vaccines to the National immunization program in the Republic of Korea. Vaccine 2014;32:6049-53.

35 Al Awaidy S. The National Committee for vaccines regulation and surveillance of vaccine-preventable diseases in the Sultanate of Oman: evidence-based approach and consensus decision-making. Vaccine 2010;28 Suppl 1:A39-41.

36 Hadisoemarto PF, Reich MR, Castro MC. Introduction of pentavalent vaccine in Indonesia: a policy analysis. Health Policy Plan 2016;31:1079-88.

37 van der Putten IM, Paulus ATG, Hiligsmann M, et al. EvidenceInformed vaccine decision making: the introduction of human papilloma virus (HPV) vaccination in the Netherlands. Health Policy 2019;123:260-266.

38 Burchett HED, Mounier-Jack S, Griffiths UK, et al. National decisionmaking on adopting new vaccines: a systematic review. Health Policy Plan 2012;27 Suppl 2:ii62-76.

39 Hadisoemarto PF, Reich MR, Castro MC. Introduction of pentavalent vaccine in Indonesia: a policy analysis. Health Policy Plan 2016;31:1079-88.

40 Kant L. NTAGI Subcommittee recommendations on Haemophilus influenzae type B (Hib) vaccine introduction in India. Indian Pediatr 2009;46:945-54.

41 Makinen M, Kaddar M, Molldrem V, et al. New vaccine adoption in lower-middle-income countries. Health Policy Plan 2012;27 Suppl 2:ii39-49.

42 van der Putten IM, Evers SMAA, Deogaonkar R, et al. Stakeholders perception on including broader economic impact of vaccines in economic evaluations in low and middle income countries: a mixed methods study. BMC Public Health 2015;15:356.

43 Dawa J, Chaves SS, Ba Nguz A, et al. Developing a seasonal influenza vaccine recommendation in Kenya: process and challenges faced by the National immunization technical Advisory group (NITAG). Vaccine 2019;37:464-72.

44 Muliyil JP, Bhan MK, Bhattacharya SK, et al. NTAGI Subcommittee recommendations on Haemophilus influenzae type $B(\mathrm{Hib})$ vaccine introduction in India. Indian Pediatr 2009:46:945-54.
45 Pooripussarakul S, Riewpaiboon A, Bishai D, et al. What criteria do decision makers in Thailand use to set priorities for vaccine introduction? BMC Public Health 2016;16:684.

46 Baltussen R, Marsh K, Thokala P, et al. Multicriteria decision analysis to support health technology assessment agencies: benefits, limitations, and the way forward. Value Health 2019;22:1283-8.

47 Botwright S, Giersing BK, Meltzer MI, et al. The CAPACITI DecisionSupport tool for national immunization programs. Value Health 2021:24:1150-7.

48 Dorji T, Tshomo U, Phuntsho S, et al. Introduction of a national HPV vaccination program into Bhutan. Vaccine 2015;33:3726-30.

49 Fletcher MA, Tetelboum R, Fritzell B. Time to recommend pneumococcal vaccination for all children in Europe: experience in France. Eur J Pediatr 2002;161 Suppl 2:S132-4.

50 Garpenholt $\mathrm{O}$, Fredlund $\mathrm{H}$, Timpka T. Immunization against Haemophilus influenzae type $b$ in Sweden--a study of the introduction process. Scand J Public Health 2001;29:271-8.

$51 \mathrm{Ngcobo}$ NJ, Cameron NA. The decision making process on new vaccines introduction in South Africa. Vaccine 2012;30 Suppl 3:C9-13.

52 Marsh KD, Sculpher M, Caro JJ, et al. The use of MCDA in HTa: great potential, but more effort needed. Value Health 2018;21:394-7.

53 Marsh K, Thokala P, Youngkong S, et al. Incorporating MCDA into HTa: challenges and potential solutions, with a focus on lower income settings. Cost Eff Resour Alloc 2018;16:43.

54 Wilson ECF, Peacock SJ, Ruta D. Priority setting in practice: what is the best way to compare costs and benefits? Health Econ 2009;18:467-78.

55 Airoldi M, Morton A, Smith J. Healthcare prioritisation at the local level: a socio-technical approach 2011.

56 Khan Al, Levin A, Chao DL, et al. The impact and cost-effectiveness of controlling cholera through the use of oral cholera vaccines in urban Bangladesh: a disease modeling and economic analysis. PLoS Negl Trop Dis 2018;12:e0006652.

57 World Health Organization. Cholera, 2014. Wkly Epidemiol Rec 2015;90:517-44.

58 Hossain MA, AHMM L, Rayhan MI. Population projection of Bangladesh: dynamics and trends 2011-2061. Dhaka, Bangladesh: Bangladesh Bureay of Statistics, Statistics and Information Division, Ministry of Planning, 2015.

59 Eisenberg MC, Robertson SL, Tien JH. Identifiability and estimation of multiple transmission pathways in cholera and waterborne disease. J Theor Biol 2013;324:84-102.

60 Haider S, Chaikledkaew U, Thavorncharoensap M. CostEffectiveness of dengue vaccine introduction in Dhaka City, Bangladesh. HTAsiaLink. Thailand: Chiang Mai, 2018.

61 World Health Organization. Dengue vaccine: who position paper July 2016. Wkly Epidemiol Rec 2016;91:349-64.

62 World Health Organization. Dengue vaccine: WHO position paper, July 2016 - recommendations. Vaccine 2017;35:1200-1.

63 Mahumud RA, Gow J, Alam K, et al. Cost-Effectiveness of the introduction of two-dose bi-valent (Cervarix) and quadrivalent (Gardasil) HPV vaccination for adolescent girls in Bangladesh. Vaccine 2020;38:165-72.

64 Services DGoH. National strategy for cervical cancer prevention and control Bangladesh (2017-2022): Directorate General of health services; 2017.

65 Jit M, Brisson M, Portnoy A, et al. Cost-Effectiveness of female human papillomavirus vaccination in 179 countries: a prime modelling study. Lancet Glob Health 2014;2:e406-14.

66 Riesen M, Garcia V, Low N, et al. Modeling the consequences of regional heterogeneity in human papillomavirus (HPV) vaccination uptake on transmission in Switzerland. Vaccine 2017;35:7312-21.

67 Ahmed M, Aleem MA, Roguski K, et al. Estimates of seasonal influenza-associated mortality in Bangladesh, 2010-2012. Influenza Other Respir Viruses 2018;12:65-71.

68 Brooks WA, Goswami D, Rahman M, et al. Influenza is a major contributor to childhood pneumonia in a tropical developing country. Pediatr Infect Dis J 2010;29:216-21.

69 Zaman K, Roy E, Arifeen SE, et al. Effectiveness of maternal influenza immunization in mothers and infants. $N$ Engl J Med 2008;359:1555-64.

70 Orenstein EW, Orenstein LAV, Diarra K, et al. Cost-Effectiveness of maternal influenza immunization in Bamako, Mali: a decision analysis. PLoS One 2017;12:e0171499.

71 van den Driessche P. Reproduction numbers of infectious disease models. Infect Dis Model 2017;2:288-303.

72 Touch S, Suraratdecha C, Samnang C, et al. A cost-effectiveness analysis of Japanese encephalitis vaccine in Cambodia. Vaccine 2010;28:4593-9. 
73 World Health Organization. Japanese encephalitis vaccines: who position paper. Weekly Epidemiological Record= Relevé épidémiologique hebdomadaire 2015;90:69-88.

74 Tandan JB, Ohrr H, Sohn YM, et al. Single dose of SA 14-142 vaccine provides long-term protection against Japanese encephalitis: a case-control study in Nepalese children 5 years after immunization. drjbtandan@yahoo.com. Vaccine 2007;25:5041-5.

75 . Estimation of parameters and basic reproductive ratio for Japanese encephalitis transmission in the Philippines using a sequential Monte Carlo filter. 2017 IEEE Conference on Control Technology and Applications (CCTA). IEEE, 2017.

76 Sarker AR, Sultana M, Mahumud RA, et al. Cost-Effectiveness analysis of introducing universal childhood rotavirus vaccination in Bangladesh. Hum Vaccin Immunother 2018;14:189-98.

77 Troeger C, Khalil IA, Rao PC, et al. Rotavirus vaccination and the global burden of rotavirus diarrhea among children younger than 5 years. JAMA Pediatr 2018;172:958-65.

78 Zaman K, Dang DA, Victor JC, et al. Efficacy of pentavalent rotavirus vaccine against severe rotavirus gastroenteritis in infants in developing countries in Asia: a randomised, double-blind, placebocontrolled trial. Lancet 2010;376:615-23.

79 Antillón M, Bilcke J, Paltiel AD, et al. Cost-Effectiveness analysis of typhoid conjugate vaccines in five endemic low- and middle-income settings. Vaccine 2017;35:3506-14.

80 Marchello CS, Hong CY, Crump JA. Global typhoid fever incidence: a systematic review and meta-analysis. Clin Infect Dis 2019;68:S105-16.

81 Yu AT, Amin N, Rahman MW, et al. Case-Fatality ratio of blood culture-confirmed typhoid fever in Dhaka, Bangladesh. $J$ Infect Dis 2018;218:S222-6.

82 Shakya M, Colin-Jones R, Theiss-Nyland K, et al. Phase 3 efficacy analysis of a typhoid conjugate vaccine trial in Nepal. N Engl J Med 2019;381:2209-18.

83 Pitzer VE, Bowles CC, Baker S, et al. Predicting the impact of vaccination on the transmission dynamics of typhoid in South Asia: a mathematical modeling study. PLoS Negl Trop Dis 2014;8:e2642. 